\title{
Flight dynamics of economically important aphid species collected in 2007-2011 in the Silesian Province using a Johnson's aspirator
}

\author{
Dynamika lotów ważniejszych gospodarczo gatunków mszyc \\ odławianych w latach 2007-2011 przy użyciu aspiratora Johnsona \\ na terenie województwa śląskiego
}

\author{
Anna Gałuszka*, Sławomir Drzewiecki, Andrzej Wolski
}

\begin{abstract}
Summary
The studies on aphid flights using Johnson's aspirator in the Silesian Province in southern Poland began in 2007. Regularly captured insect species according to the list of 9 aphid species recommended for observation by the Institute of Plant Protection - National Research Institute (IPP - NRI) in Poznań, allowed comparing aphid incidence over the 5-year period. The greatest abundance of aphids was reported in the spring and autumn. The most numerous species were Rhopalosiphum padi (L.) and Anoecia corni (F.). Aphid flight data were regularly posted on the webpage of the IPP - NRI in Poznań to indicate potential risks for growers.
\end{abstract}

Key words: Johnson's suction trap; aphid flight dynamics; Rhopalosiphum padi; Anoecia corni

\section{Streszczenie}

Badania nad przelotami mszyc przy użyciu aspiratora Johnsona na terenie południowej Polski w województwie śląskim zostały rozpoczęte w 2007 roku. Regularnie odławiane próby owadów w oparciu o listę 9 gatunków mszyc wskazanych do obserwacji przez Instytut Ochrony Roślin - Państwowy Instytut Badawczy (IOR - PIB) w Poznaniu umożliwiło porównanie nasilenia występowania tych szkodników w okresie pięciu lat badań. Największe natężenie przelotów mszyc obserwowano wiosną oraz jesienią. Najliczniej reprezentowanymi gatunkami były Rhopalosiphum padi (L.) oraz Anoecia corni (F.). Wyniki rejestracji lotów mszyc zamieszczane były na bieżąco na stronie internetowej IOR - PIB w Poznaniu, w celu wskazania zagrożeń dla producentów rolnych.

Słowa kluczowe: aspirator Johnsona; dynamika przelotów mszyc; Rhopalosiphum padi; Anoecia corni

Instytut Ochrony Roślin - Państwowy Instytut Badawczy

Zakład Badania Skuteczności Środków Ochrony Roślin

Oddział Sośnicowice

Gliwicka 29, 44-153 Sośnicowice

*corresponding author: a.galuszka@ior.gliwice.pl 


\section{Wstęp / Introduction}

Mszyce jako owady charakteryzujące się dużymi zdolnościami adaptacyjnymi do zmiennych warunków środowiskowych są szczególnie ważną grupą agrofagów (Strażyński i wsp. 2011; Parry 2013). Powodują straty bezpośrednie przez wysysanie soków z roślin i ich osłabienie oraz pośrednie, będąc wektorami wielu groźnych wirusów (Ruszkowska 2006; Klueken i wsp. 2009). Gatunki, takie jak Rhopalosiphum padi i Sitobion avenae, które zasiedlają zboża, występując masowo mogą powodować straty plonu do 20\% (Ruszkowska 1993). Rozprzestrzenianie się mszyc i zasiedlanie nowych obszarów przez pojawiające się cyklicznie morfy uskrzydlone, które mogą pokonywać znaczne odległości, było przedmiotem badań prowadzonych przy użyciu aspiratora Johnsona. Aparat ten został zainstalowany na terenie Instytutu Ochrony Roślin - Państwowego Instytutu Badawczego (IOR - PIB), Oddział Sośnicowice w 2006 roku $\mathrm{i}$ jest jedynym tego typu urządzeniem w południowej części kraju (Złotkowski 2008). Wyniki rejestracji lotów odławianych gatunków mszyc umieszczane były na bieżąco na stronie internetowej Zakładu Metod Prognozowania i Rejestracji Agrofagów IOR - PIB w Poznaniu dostępnej dla producentów rolnych (www.ior.poznan.pl) w celu wskazania zagrożeń.

Celem realizowanych badań było określenie składu, dynamiki migracji oraz liczebności najważniejszych gospodarczo gatunków mszyc.

\section{Materiały i metody / Materials and methods}

Aspirator Johnsona usytuowany jest na terenie IOR PIB, Oddział Sośnicowice, około $10 \mathrm{~km}$ od miejscowości Gliwice, w województwie śląskim (współrzędne geograficzne: szerokość 50.27099, długość 18.54144). Urządzenie znajduje się $\mathrm{w}$ bezpośrednim otoczeniu pól uprawnych z przeważającym udziałem zbóż w strukturze zasiewów oraz kompleksów leśnych. Stalowa konstrukcja aspiratora, umieszczona na płycie betonowej posiada wentylator zasysający powietrze przez rurę o długości 9 metrów i średnicy $250 \mathrm{~mm}$. Całkowita wysokość urządzenia wynosi 12,2 m powyżej poziomu terenu. Próby zebrane za pomocą aspiratora Johnsona przedstawiają stan fauny migrującej na terenie o promieniu do $80 \mathrm{~km}$ od miejsca zainstalowania pułapki (Taylor 1951).

Badania prowadzono w latach 2007-2011, w okresie od początku maja do połowy listopada. Aspirator pracował $\mathrm{w}$ godzinach od 6.00 do 22.00 , a próby pobierano raz dziennie o godzinie 12. Spośród odłowionych owadów wyselekcjonowano mszyce, które następnie oznaczano do gatunku. Zebrane okazy archiwizowano w celu stworzenia kolekcji gatunków występujących w regionie. Korzystano z kluczy do identyfikacji gatunków mszyc (Szelegiewicz 1968; Müller 1976; Taylor 1980). Oznaczony i zaetykietowany materiał zabezpieczano w 75\% alkoholu etylowym.

Wyniki poddano analizie statystycznej wykorzystując program STATISTICA v. 8.0. Zastosowano analizę wariancji ANOVA. Wyniki porównano za pomocą testu statystycznego Duncana przy poziomie istotności $\alpha=0,05$.
Wskaźnik dominacji osobniczej (D) dla zebranej afidofauny obliczono według wzoru (Kasprzak i Niedbała 1981):

$$
\mathrm{D}=\mathrm{n} / \mathrm{N} \times 100 \%
$$

n - liczba osobników danego gatunku występujących w próbie w określonym czasie,

$\mathrm{N}$ - liczba wszystkich osobników mszyc odłowionych aspiratorem w określonym czasie.

Wszystkie gatunki sklasyfikowano w 5 klasach dominacji tj.: D5: eudominanci - powyżej 10\% liczby osobników w próbie, D4: dominanci - 5,1-10,0\%, D3: subdominanci - 2,1-5,0\%, D2: recedenci - 1,1-2,0\%, D1: subrecedenci - poniżej 1\% (Złotkowski i Bandyk 2012).

\section{Wyniki i dyskusja / Results and discussion}

Regularnie odławiane owady pozwoliły na analizę zmian w liczebności oraz w składzie gatunkowym uskrzydlonych mszyc w latach 2007-2011.W niniejszym opracowaniu wzięto pod uwagę 9 gatunków mszyc wskazanych przez IOR - PIB w Poznaniu, wybranych jako istotne dla upraw rolniczych. Obserwowano głównie gatunki żerujące na zbożach oraz w uprawach buraków, ziemniaków i rzepaku: Acyrthosiphon pisum, Aphis fabae, A. frangulae, Anoecia corni, Brevicoryne brassicae, Metopolophium dirhodum, Myzus persicae, Rhopalosiphum padi oraz Sitobion avenae (Złotkowski 2010a). Nasilenie lotów tych gatunków było zróżnicowane w zależności od pory roku oraz roku obserwacji.

Łączna liczba mszyc odłowionych przy pomocy aspiratora Johnsona, we wszystkich latach badań wyniosła ponad 50530 osobników (tab. 1). Największą liczebność mszyc stwierdzono w 2010 roku, tj. 19299 osobników. W 2011 roku odłowiono łącznie 14779 mszyc. Mniej licznie owady te, notowane były w 2009 roku (7271 osobników). W latach 2007-2008 obserwowano najmniejszą liczebność mszyc, odłowiono odpowiednio 4285 i 4896 uskrzydlonych morf. Zdecydowanie najliczniejszym gatunkiem we wszystkich latach badań (za wyjątkiem 2010 roku) była $R$. padi, której udział procentowy wynosił w poszczególnych latach od 17,2 do 28\%. Gatunek ten był również najliczniej odławiany w badaniach Strażyńskiego (2006) i Strażyńskiego i wsp. (2011). Autorzy wykazywali od 40 do $76 \% R$. padi w latach prowadzenia odłowów. W niniejszych badaniach licznie wystąpiły również mszyce należące do gatunku $A$. corni, którego udział w zależności od roku wynosił od 7,7 do 12,2\%. Badania prowadzone przez Wilkaniec i wsp. (2012), wskazują również na znaczny udział tego gatunku w materiale zebranym za pomocą pułapek Moerickego i pułapek świetlnych. Odsetek pozostałych gatunków mszyc nie przekraczał 3,1 niezależnie od roku badań.

Do określenia wskaźnika dominacji osobniczej przyjęto wartości wieloletnich średnich sum liczebności poszczególnych gatunków owadów, na podstawie metodyki Złotkowskiego i Bandyka (2012). Najliczniejszą grupę stanowiły gatunki należące do klasy subrecedentów (tab. 1). Do klasy eudominantów i dominantów zaszeregowano po 1 gatunku mszyc (odpowiednio R. padi i A. corni). Odsetek $R$. padi w 4 z 5 lat badań przekraczał 10. Liczebność 
Tabela 1. Skład gatunkowy uskrzydlonych morf mszyc w latach badań

Table 1. Species composition of winged aphid morphs in the years of the studies

\begin{tabular}{|c|c|c|c|c|c|c|c|c|c|c|c|c|c|}
\hline \multirow[b]{2}{*}{ Gatunek - Species } & \multicolumn{10}{|c|}{ Rok/liczba mszyc - Year/number of aphids } & \multirow{2}{*}{$\begin{array}{c}\text { Razem } \\
\text { Total }\end{array}$} & \multirow[b]{2}{*}[\%]{} & \multirow{2}{*}{$\begin{array}{c}\text { Klasa } \\
\text { domi- } \\
\text { nacji } \\
\text { Class of } \\
\text { domi- } \\
\text { nance }\end{array}$} \\
\hline & 2007 & {$[\%]$} & 2008 & {$[\%]$} & 2009 & {$[\%]$} & 2010 & {$[\%]$} & 2011 & {$[\%]$} & & & \\
\hline $\begin{array}{l}\text { Mszyca czeremchowo-zbożowa } \\
\text { Rhopalosiphum padi L. }\end{array}$ & 735 & 17,2 & 1371 & 28,0 & 1286 & 17,7 & 598 & 3,1 & 2777 & 18,8 & 6767 & 13,4 & D5 \\
\hline $\begin{array}{l}\text { Zrostek świdwowo-zbożowy } \\
\text { Anoecia corni F. }\end{array}$ & 332 & 7,7 & 448 & 9,2 & 426 & 5,9 & 2364 & 12,2 & 1256 & 8,5 & 4826 & 9,6 & D4 \\
\hline $\begin{array}{l}\text { Mszyca trzmielinowo-burakowa } \\
\text { Aphis fabae Scop. }\end{array}$ & 128 & 3,0 & 76 & 1,6 & 83 & 1,1 & 133 & 0,7 & 7 & 0 & 427 & 0,8 & D1 \\
\hline $\begin{array}{l}\text { Mszyca brzoskwiniowa } \\
\text { Myzus persicae Sultz }\end{array}$ & 0 & 0 & 89 & 1,8 & 132 & 1,8 & 172 & 0,9 & 6 & 0 & 399 & 0,8 & D1 \\
\hline $\begin{array}{l}\text { Mszyca zbożowa } \\
\text { Sitobion avenae } \mathrm{F} \text {. }\end{array}$ & 48 & 1,1 & 17 & 0,3 & 58 & 0,8 & 76 & 0,4 & 100 & 0,7 & 299 & 0,6 & D1 \\
\hline $\begin{array}{l}\text { Mszyca kapuściana } \\
\text { Brevicoryne brassicae L. }\end{array}$ & 0 & 0 & 103 & 2,1 & 87 & 1,2 & 102 & 0,5 & 5 & 0 & 297 & 0,6 & D1 \\
\hline $\begin{array}{l}\text { Mszyca grochowa } \\
\text { Acyrthosiphon pisum Harris }\end{array}$ & 134 & 3,1 & 56 & 1,1 & 35 & 0,5 & 47 & 0,2 & 9 & 0,1 & 281 & 0,6 & D1 \\
\hline $\begin{array}{l}\text { Mszyca różano-zbożowa } \\
\text { Metopolophium dirhodum } \\
\text { Walk. }\end{array}$ & 27 & 0,6 & 10 & 0,2 & 12 & 0,2 & 9 & 0 & 31 & 0,2 & 89 & 0,2 & D1 \\
\hline $\begin{array}{l}\text { Mszyca kruszynowo- } \\
\text { ziemniaczana } \\
\text { Aphis frangulae Kalt. }\end{array}$ & 0 & 0 & 0 & 0 & 10 & 0,1 & 18 & 0,1 & 0 & 0 & 28 & 0,1 & D1 \\
\hline Pozostałe - Other & 2881 & 67,2 & 2726 & 55,7 & 5142 & 70,7 & 15780 & 81,8 & 10588 & 71,6 & 37117 & 73,5 & - \\
\hline Suma mszyc - Total aphids & 4285 & 100 & 4896 & 100 & 7271 & 100 & 19299 & 100 & 14779 & 100 & 50530 & 100 & - \\
\hline
\end{tabular}

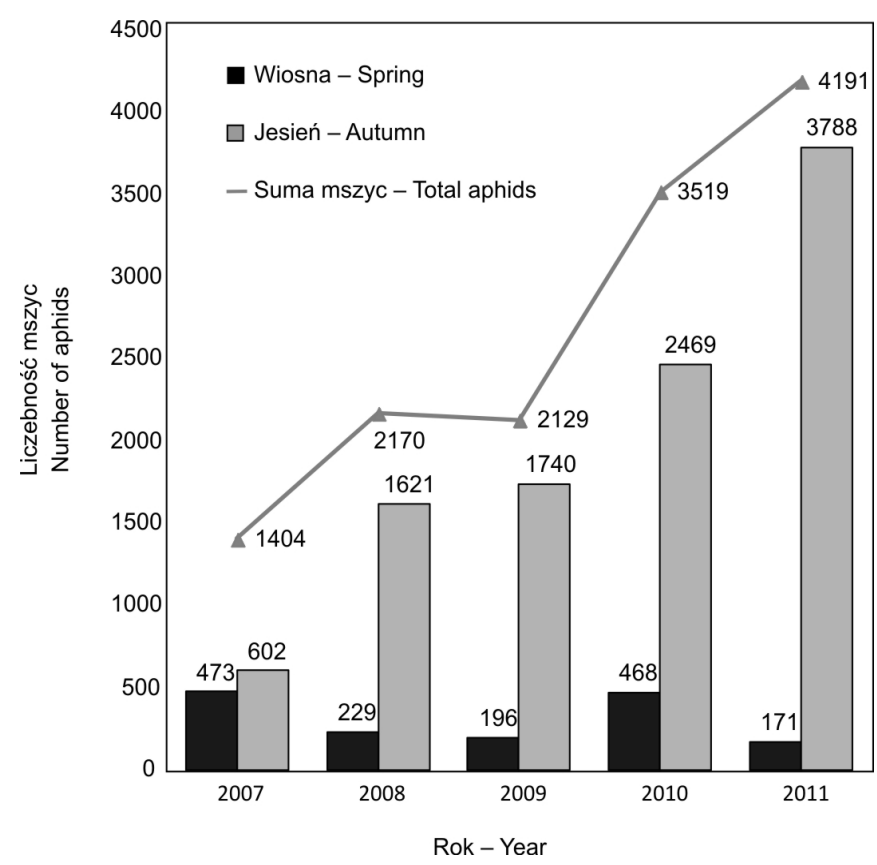

Rys. 1. Porównanie wiosennego i jesiennego nasilenia przelotów mszyc w latach 2007-2011

Fig. 1. Comparison of aphid flight activity during the spring and autumn in 2007-2011

A. corni wyrażona w procentach w stosunku do ogółu odłowionych mszyc, w większości lat klasyfikowała ten gatunek w grupie dominantów. Podobne wyniki w swoich badaniach prowadzonych na terenie Wielkopolski uzyskali Złotkowski i Bandyk (2012), włączając $R$. padi do klasy eudominantów. $A$. corni była najczęściej klasyfikowana przez wyżej wymienionych autorów do grupy eudominantów lub dominantów. 


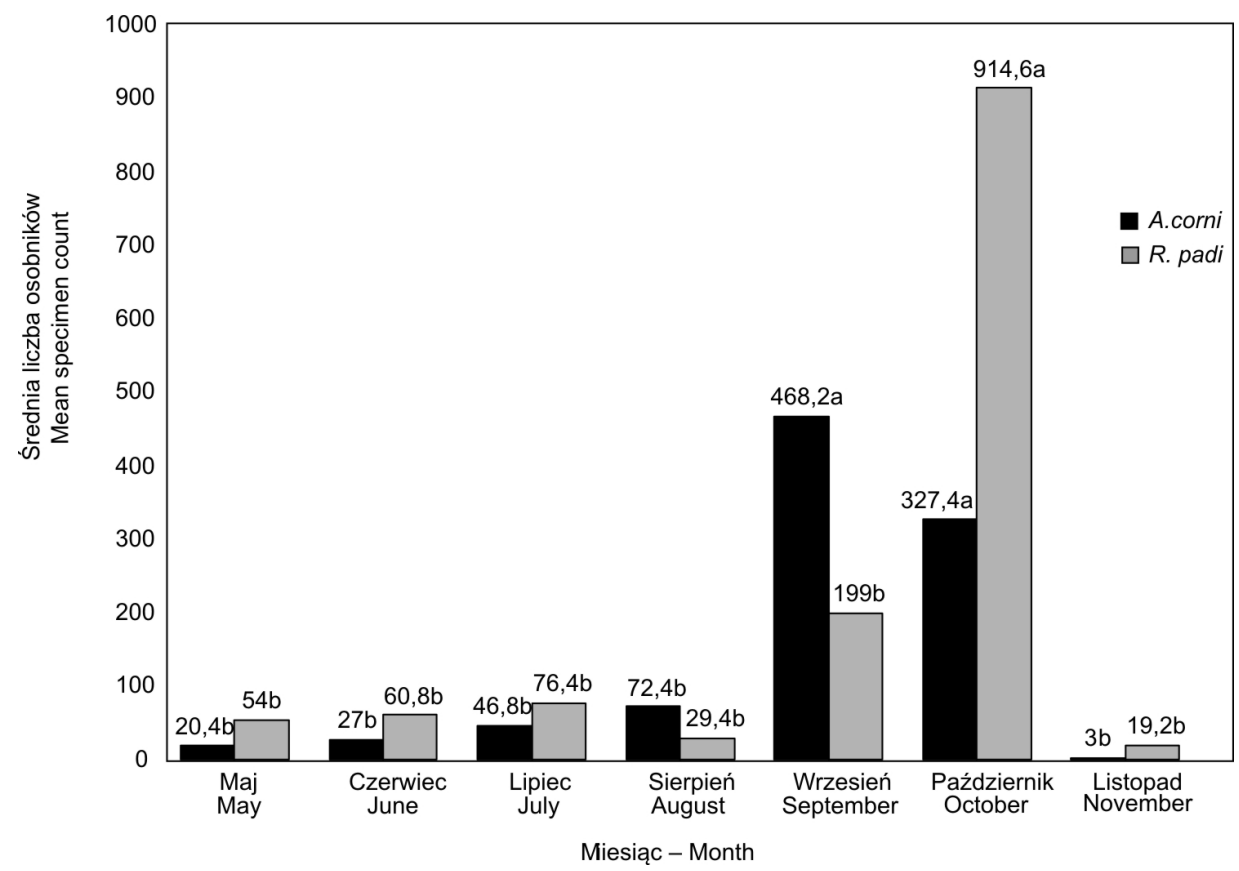

Rys. 2. Średnia liczebność gatunków dominujących: R. padi oraz A. corni w latach 2007-2011

Fig. 2. Average number of dominant species: R. padi and A. corni in 2007-2011

Analizując przebieg migracji oznaczonych gatunków mszyc w okresie badawczym stwierdzono znaczny wzrost ich liczebności (rys. 1). Wiosną odławiano od 171 do 473 uskrzydlonych morf. Uzyskane wartości liczebności w pięcioletnim okresie badań nie charakteryzowały się trendem wzrostowym lub spadkowym w przeciwieństwie do okresu jesiennego z wyraźną tendencją wzrostową. Liczba mszyc odnotowywana jesienią wahała się od 602 w 2007 roku do 3788 osobników w 2011 roku. Biorąc pod uwagę dość krótki okres prowadzenia odłowów, trudno jednoznacznie wskazać przyczyny regularnego wzrostu liczby mszyc. Jak pokazują wcześniejsze badania innych autorów, udział procentowy poszczególnych odławianych gatunków przy pomocy aspiratora Johnsona może regularnie wzrastać przez kilka lat, po czym następuje gwałtowne załamanie ich liczebności (Złotkowski 2011).

W badaniach własnych najliczniej reprezentowanymi gatunkami były $R$. padi i $A$. corni. Dominację tych gatunków w zebranym materiale stwierdzili również Złotkowski i Wolski (2008). Na rysunku 2. przedstawiono ich średnią liczbę w okresie prowadzenia odłowów (2007-2011) porównując uzyskane wartości w poszczególnych miesiącach dla obydwóch gatunków mszyc. Średnia liczebność $R$. padi w okresie wiosenno-letnim (maj-sierpień) wyniosła od 29,4 do 76,4 osobników. W październiku odnotowano istotny wzrost średniej liczebności tego gatunku w porównaniu do poprzedniego okresu. Wyniki te są zgodne z obserwacjami innych autorów wskazującymi na zdecydowanie większą migrację $R$. padi w okresie jesiennym (Strażyński 2010; Złotkowski 2010a).

Podobne zależności stwierdzono w przypadku intensywności lotów A. corni. Średnia liczebność wymienionego gatunku mszycy obserwowana we wrześniu i październiku wynosząca odpowiednio 327,4 i 468,2 osobników różniła się istotnie od wartości uzyskanych we wcześniejszych miesiącach. Jesienna dominacja lotów
A. corni była obserwowana już w latach 2001-2004 w badaniach Złotkowskiego (2005) oraz Strażyńskiego i wsp. (2011).

Jednym z powodów większego nasilenia przelotów mszyc w okresie jesiennym we wszystkich latach badań może być reemigracja tych owadów na rośliny, na których następuje ich zimowanie. W przypadku $R$. padi jesienna dominacja obserwowana jest na terenie naszego kraju od niedawna i związana jest ze zróżnicowaniem w obrębie jego populacji, z wyraźną przewagą form anholocyklicznych przy równoczesnym mniejszym udziale samców (Strażyński i Trzmiel 2008). Anholocykliczne formy $R$. padi uważane są w naszym kraju za najważniejsze wektory wirusa żółtej karłowatości jęczmienia (BYDV), szczególnie groźnego dla zbóż ozimych (Ruszkowska 2002; Strażyński i wsp. 2011).

Uzyskane dzięki badaniom przy użyciu aspiratora informacje dotyczące jesiennych migracji $R$. padi mogą być pomocne w ustalaniu terminu nalotu na plantację (Ruszkowska i Strażyński 2007; Złotkowski 2010b). Kontynuacja tych badań wraz $\mathrm{z}$ danymi meteorologicznymi umożliwi stworzenie odpowiednich systemów ,wczesnego ostrzegania" przed zagrożeniem wynikającym z występowania omawianej grupy owadów.

\section{Wnioski / Conclusions}

1. W pięcioletnich odłowach mszyc za pomocą aspiratora Johnsona stwierdzono wyraźną dominację dwóch gatunków: $R$. padi oraz $A$. corni w stosunku do ogółu odłowionych mszyc w poszczególnych latach badań.

2. Na podstawie liczebności mszyc odławianych w latach 2007-2011 stwierdzono zdecydowaną dominację jesiennych migracji tych owadów w porównaniu do lotów obserwowanych w okresie wiosennym. 
3. Zastosowanie pułapki ssącej Johnsona w okresie jesiennym jest przydatne w określeniu optymalnego terminu wykonania zabiegu zwalczającego $R$. padi, głównego wektora żółtej wirusowej karłowatości jęczmienia (BYDV).

\section{Literatura / References}

Kasprzak K., Niedbała W. 1981. Wskaźniki biocenotyczne stosowane przy porządkowaniu i analizie danych w badaniach ilościowych. s. 397-416. W: „Metody stosowane w zoologii gleby” (M. Górny, L. Grüm, red.). PWN, Warszawa, 483 ss.

Klueken A.M., Hau B., Ulber B., Poehling H.-M. 2009. Forecasting migration of cereal aphids (Hemiptera: Aphididae) in autumn and spring. Journal of Applied Entomology 133 (9): 328-344.

Müller F.P. 1976. Mszyce - szkodniki roślin: terenowy klucz do oznaczania. Instytut Zoologii PAN, Warszawa, 119 ss.

Parry H.R. 2013. Cereal aphid movement: general principles and simulation modeling. Movement Ecology 11 (14): 1-15.

Ruszkowska M. 1993. Rola terminów zabiegów chemicznych w zwalczaniu mszyc zbożowych. [Importance of the terms of treatment chemical control on the winter wheat before aphids]. Materiały 33. Sesji Naukowej Instytutu Ochrony Roślin, cz. 2: 62-65.

Ruszkowska M. 2002. Przekształcenia cyklicznej partenogenezy mszycy Rhopalosiphum padi (L.) (Homoptera: Aphidoidea) - znaczenie zjawiska w adaptacji środowiskowej. Rozprawy Naukowe Instytutu Ochrony Roślin 8, 33 ss.

Ruszkowska M. 2006. Uwarunkowania klimatyczne w rozprzestrzenianiu najważniejszych wektorów chorób wirusowych na zbożach w badanych regionach Polski. [Permanent and cyclic parthenogenesis of Rhopalosiphum padi (L.) (Homoptera: Aphidoidea) across different climate regions in Poland]. Progress in Plant Protection/Postępy w Ochronie Roślin 46 (1): 276-283.

Ruszkowska M., Strażyński P. 2007. Mszyce na oziminach. Instytut Ochrony Roślin, Poznań, 23 ss.

Strażyński P. 2006. Znaczenie rejestracji lotów ważniejszych gospodarczo gatunków i form mszyc w odłowach aspiratorem Johnsona w Poznaniu w latach 2003-2005 w integrowanych metodach ochrony roślin. [The importance of registration of flights of the economically important species and forms of aphids in Johnson's suction trap in Poznań in 2003-2005 in integrated pest management]. Progress in Plant Protection/Postępy w Ochronie Roślin 46 (2): 395-398.

Strażyński P. 2010. Population structure of Rhopalosiphum padi (Linnaeus, 1758)/Hemiptera, Aphioidea/ in Wielkopolska region in 2003-2008 in the context of winter cereals threat of BYDV expansion. p. 91-105. In: „Aphids and Other Hemipterous Insects”, Vol. 16 (W. Goszczyński, A. Herczek, B. Leszczyński, G. Łabanowski, E. Podsiadło, R. Rakauskas, M. Ruszkowska, B. Wilkaniec, W. Wojciechowski, eds.). The John Paul II Catholic University of Lublin, 125 pp.

Strażyński P., Ruszkowska M., Węgorek P. 2011. Dynamika lotów mszyc w latach 2008-2010 najliczniej odławianych w Poznaniu aspiratorem Johnsona. [Flights dynamics of aphids caught numerously by Johnson's suction trap in Poznań in 2008-2010]. Progress in Plant Protection/Postępy w Ochronie Roślin 51 (1): 213-216.

Strażyński P., Trzmiel K. 2008. Struktura jesiennych populacji mszycy czeremchowo-zbożowej (Rhopalosiphum padi L.) - ocena realnego zagrożenia żółtą karłowatością jęczmienia w zróżnicowanych klimatycznie regionach Polski. [Structure of autumn populations of bird cherry-oat aphid (Rhopalosiphum padi L.) - practical importance in a consideration of real threat of BYDV in a different regions of Poland]. Progress in Plant Protection/Postępy w Ochronie Roślin 48 (3): 804-807.

Szelegiewicz H. 1968. Mszyce (Aphidodea) Katalog fauny Polski. XXI, Zeszyt 4. PWN, Warszawa, 316 ss.

Taylor L.R. 1951. An improved suction trap for insect. Annals of Applied Biology 38: 582-591.

Taylor L.R. 1980. A Handbook for Aphid Identification. Euraphid - Rothamsted, Experimental Station, Rothamsted, 171 pp.

Wilkaniec B., Lewandowski R., Borowiak-Sobkowiak B. 2012. The effectiveness of catching aphids (Hemiptera: Sternorrhyncha: Aphidinea) in Moericke and light traps. Journal of Plant Protection Research 52 (2): 259-263.

Złotkowski J. 2005. Rejestracja sezonowych lotów ważniejszych gospodarczo mszyc w odłowach aspiratorem zainstalowanym na terenie pracowni doświadczalnictwa polowego w Winnej Górze w latach 2001-2004. [Record of seasonal flights of economically important aphids in catches by Johnsons aspirator in 2001-2004]. Progress in Plant Protection/Postępy w Ochronie Roślin 45 (2): $1229-1232$.

Złotkowski J. 2008. Methods to collecting aerial aphid fauna and their significance in plant protection. p. 187-192. In: „Aphids and Other Hemipterous Insects”, Vol. 14 (W. Goszczyński, A. Herczek, B. Leszczyński, G. Łabanowski, E. Podsiadło, R. Rakauskas, M. Ruszkowska, B. Wilkaniec, W. Wojciechowski, eds.). The John Paul II Catholic University of Lublin, 198 pp.

Złotkowski J. 2010a. Skład gatunkowy mszyc migrujących w Wielkopolsce na podstawie odłowów aspiratorem w Winnej Górze. [Species composition of migratory aphids based on catches by Johnsons aspirator in Winna Góra in 2002-2009]. Progress in Plant Protection/Postępy w Ochronie Roślin 50 (1): 186-190.

Złotkowski J. 2010b. Changes in aphid migration dynamics around Winna Góra (Wielkopolska) in 2000-2008. p. 79-90. In: „Aphids and Other Hemipterous Insects”, Vol. 16 (W. Goszczyński, A. Herczek, B. Leszczyński, G. Łabanowski, E. Podsiadło, R. Rakauskas, M. Ruszkowska, B. Wilkaniec, W. Wojciechowski, eds.). The John Paul II Catholic University of Lublin, 125 pp.

Złotkowski J. 2011. Znaczenie aspiratora Johnsona w badaniach migracji mszyc w Polsce w latach 1973-2010. [Significance of Johnson's suction trap in research on aphid migration in Poland in 1973-2010]. Progress in Plant Protection/Postępy w Ochronie Roślin 51 (1): 158-163.

Złotkowski J., Bandyk A. 2012. Charakterystyka zmian w strukturze składu gatunkowego mszyc migrujących w odłowach aspiratorem Johnsona w latach 1999-2010. [Characteristic of the changes in the structure of aphid species composition based on catches of Johnson's suction trap in 1999-2010]. Progress in Plant Protection/Postępy w Ochronie Roślin 52 (2): 252-258.

Złotkowski J., Wolski A. 2008. Badania nad migracjami mszyc przy użyciu aspiratora Johnsona w Winnej Górze w latach $2000-2007$. [Studies on migrations of aphids with the use of Johnson's suction trap in Winna Góra during the period of 2000-2007]. Progress in Plant Protection/Postępy w Ochronie Roślin 48 (3): 1013-1017. 